\title{
IMMUNODIAGNOSIS IN MEMBRANOUS NEPHROPATHY
}

DOI: 10.36740/WLek202009110

\author{
Magdalena Ratajczak', Ewa Poleszak², Tomasz Chrościcki ${ }^{3}$ \\ 'EUROIMMUN POLAND A PERKINELMER COMPANY, WROCLAW, POLAND \\ 2DEPARTMENT OF APPLIED AND SOCIAL PHARMACY, LABORATORY OF PRECLINICAL TESTING, MEDICAL UNIVERSITY OF LUBLIN, LUBLIN, POLAND \\ ${ }^{3}$ DEPARTAMENT OF REHABILITATION, CITY HOSPITAL OF TORUN, TORUN, POLAND
}

\begin{abstract}
One of the diseases leading to chronic end-stage renal disease is membranous nephropathy (MN). The main cause of this disease is the formation of antibodies to foreign and native antigens. Membranous nephropathy can be conventionally divided into 2 types: primary form (when the primary disease is unknown) and secondary form. Detection of appropriate antibodies is one of the methods to recognize and differentiate primary and secondary forms. A large role in non-invasive diagnosis of $M N$ and differentiation of the primary form from the secondary play antinuclear antibodies (ANA), antibodies against granulocyte cytoplasm (ANCA), antiglomerular basement antibodies (anti-GBM) and phospholipase A2 receptor antibodies (anti-PLA2R). Differentiation matters when choosing a treatment choice. In the primary form, it is immunosuppression, and in the form of secondary treatment, it consists in curing or controlling diseases that can cause symptoms of MN.

The aim: Analysis of serological methods helpful in immunodiagnosis of membranous nephropathy.
\end{abstract}

KEY WORDS: membranous nephropathy, immunodiagnosis, antibodies

Wiad Lek. 2020;73(9 p. I):1861-1866

\section{INTRODUCTION}

Glomerulonephritis belongs to various diseases and leads to chronic end-stage renal disease [1]. The history of membranous nephropathy dates back to 1946, when E. Bell first called this disease [2]. It belonged to a group of diseases kidney called Bright's Disease Type II 9. One of the causes may be dysregulated functioning of the immune system, and thus the production of antibodies directed against its own antigens (autoimmune) or foreign antigens. Disorders in the activation and functioning of $\mathrm{T}$ and $\mathrm{B}$ lymphocytes are responsible for autoimmune processes. Their incorrect stimulation leads to the production of antibodies against own antigens. Predisposing factors for excessive activation of lymphocytes are: bacterial, viral infections and toxins. Activation occurs by: exposing antigenic epitopes to $\mathrm{T}$ lymphocytes or by the phenomenon of molecular mimicry, in which the antibodies cross-react with the antigen of the microorganism and host tissues. Mimicry is the results from homology between host tissues and microbial antigens. T lymphocyte activation, in turn, increases cytokine and lymphokine production.

Recent reports point to the huge role of regulatory $\mathrm{T}$ lymphocytes (CD 4 and CD25) in maintaining a balance between T lymphocyte activation and autoimmunity. An example here may be patients with Goodpasture's disease in whom the level of regulatory $\mathrm{T}$ lymphocytes is much lower than in healthy patients [3].

$\mathrm{MN}$ may also have genetic background relying on genetic variation within the HLA gene. The genetic condi- tioning of various forms of glomerulonephritis is not well understood. The presence of the HLA gene is not always indicative of the disease, and the corresponding HLA allele does not condition a given MN type. Although the HLA DR2 allele predisposes to Goodpasture's disease, patients without this allele may develop this disease. The HLA DR2 allele may be present in other diseases, e.g. narcolepsy. Other genes that have not yet been identified may also be involved in the development of the disease.

There are known several mechanisms of damage the glomeruli which leading to the development of inflammation. One of ways to damage the glomeruli is through a process involving circulating immune complexes (CICs), which are deposited in the glomeruli by binding to the Fc receptor on the surface of mesangial cells, directly in the mesangium or under the epithelium. Another way is to combine antibodies with internal glomerular antigens. In the next stage, the complement system is activated, which in turn activates a cascade of proteins, leading to the development of inflammation. The complement system can be activated in a classical manner, where $\mathrm{C} 1 \mathrm{q}$ binds to the $\mathrm{Fc}$ receptor or by a lectin that has structural homology to the $\mathrm{C} 1 \mathrm{q}$ protein. Stimulation of the complement system may also occur via an alternative route involving polysaccharide antigens, polymeric IgA or endotoxins. Soluble factors may also be involved in the development of inflammation. Not all have been known so far. The identified ones include: chemokines, cytokines, growth factors, vasoactive mediators, reactive oxygen species, proteases and proteins 
involved in the coagulation process. These factors activate inflammation cells in various ways [4].

Glomerulonephritis can be conventionally divided into 2 types: primary and secondary. The primary form of glomerulonephritis can be said when the underlying disease is unknown and the cause is related to the immune system or inflammation. The secondary form is part of another systemic disease (e.g. systemic lupus) [5]. 70-80\% of patients develop primary MN, while about 20-30\% develop secondary. Diagnosis of glomerulonephritis is based on the clinical picture and histopathological examination result from kidney biopsy. Unfortunately, the clinical picture does not always correlate with the histological picture. Hence, we distinguish clinical and histological types of MN.

Clinical types of glomerulonephritis:

1. In the form of changes in urine - low proteinuria / hematuria

2. In the form of macroscopic or recurrent haematuria

3. Nephritic syndrome - oliguria, edema, proteinuria $<3 \mathrm{~g}$ / 24h, hematuria

4. Nephrotic syndrome - proteinuria $>3.5 \mathrm{~g} / 24 \mathrm{~h}$, edema, hypoalbuminaemia $(<3 \mathrm{~g} / \mathrm{dl})$, hyperlipidemia, lipiduria and edema.

5. Rapid progressive glomerulonephritis - proteinuria, hematuria, renal failure within weeks, vasculitis

6. Chronic glomerulonephritis - proteinuria, hematuria, hypertension, chronic renal failure [6].

Histological types of glomerulonephritis:

1. proliferate

- intra-capillary glomerulonephritis

- extrapillary glomerulonephritis

- mesangial glomerulonephritis

2. Membrane-proliferative glomerulonephritis

3. Membrane glomerulonephritis

4. Submicroscopic glomerulonephritis

5. Focal segmental glomerulosclerosis

6. Others

\section{REVIEW}

\section{ANTI-NUCLEAR ANTIBODIES (ANA) IN LUPUS NEPHRITIS}

Antinuclear antibodies (ANA) are a broad group of autoantibodies that are directed against components of the cell nucleus. They were first described by Coons and Kaplan in 1950 [7]. They occur in the course of many autoimmune diseases, mainly in rheumatic diseases. The incidence of antinuclear antibodies ranges from $20 \%$ to $100 \%$ [2]. In systemic lupus erythematosus (SLE), the highest incidence is achieved by anti-dsDNA (30-90\%) and anti-nucleosomes (50-95\%). SLE is a disease in which we observe clinical manifestations in various organs, including in the skin, mucous membranes, kidneys.

The most serious complication occurring in the course of SLE is lupus nephropathy - Lupus Nephritis [8-16]. It affects about $50 \%$ of patients with SLE. Despite many years of research, LN immunopathogenesis is not fully understood.
It is generally accepted that anti-double-stranded DNA (anti-dsDNA) and anti-nucleosome antibodies. Anti-nucleosome antibodies are involved in the development of the disease, which appear in the early stages of the disease before anti-dsDNA antibodies and are correlated with disease activity. There is a relationship between high anti-dsDNA antibody titers and disease activity [17].According to the latest EASI guidelines developed in March 2014. (The European Autoimmunity Standardization Initiative) ANA antibody diagnosis should be done in two stages:

$1^{\text {st }}$ STAGE - indirect immunofluorescence screening (IIFT) (Fig.1.)

$2^{\text {nd }}$ STAGE - confirmation of positive / borderline results by monospecific methods (ELISA, Immunoblot)

\section{ANTI-NEUTROPHIL CYTOPLASM ANTIBODIES (ANCA) IN VESSELS INFLAMMATIONS}

If the MN secondary form is observed in the course of vasculitis, an important element of diagnostics is the assessment of antibodies against neutrophil cytoplasm (ANCA). The recommended substrate for ANCA antibodies evaluation is ethanol-fixed human neutrophils. This way of antigen fixation allows the assessment of two basic types of fluorescence:

cANCA (cytoplasmic ANCA) (Fig. 2) for which antibodies against proteinase 3 (PR3) are most often responsible. The cANCA group also includes the less common anti-BPI (Bactericidal permeability increasing protein), anti-CAP57 and very rarely anti-myeloperoxidase (MPO) antibodies. The frequency of cANCA antibodies is (Tab. 1) [20, 21]:

pANCA (perinuclear ANCA) (Fig 3), represents a much larger group of autoantibodies. The most important are anti-myeloperoxidase (anti-MPO) antibodies. In addition, the following antibodies can also be included: anti-lactoferrin, anti-elastase, anti-BPI, anti-cathepsin G, anti-lysozyme and anti- $\beta$-Glucuronidase [21-23]. Antibodies to pANCA occur in such diseases as (Tab. 2) $[20,25,26]$.

A separate group of ANCA antibodies are so-called DNA-ANCA (formerly pANCA sensitive to formalities). They occur most often in the course of ulcerative colitis, the incidence in UC is $67 \%$. The main target antigen is lactoferrin [20, 27].

Recommendations from 1999 recommend a two-steps ANCA antibody evaluation strategy (International Consensus Statement on Testing and Reporting ANCA) (Fig. 4):

Optimal diagnostics in the case of negative results (confirmation by a mono-specific ELISA test) is aimed at detecting antibodies in patients whose antibody levels may have fallen after treatment or increased during remission. Minimal diagnostics allow the release of a negative result based only on IIFT [28].

\section{ANTI-GLOMERULAR BASEMENT ANTIBODIES (GBM) IN GOODPASTURE'S SYNDROME}

Anti-GBM antibodies occur in the course of Goodpasture's disease by many also called Anti-GMB disease. 


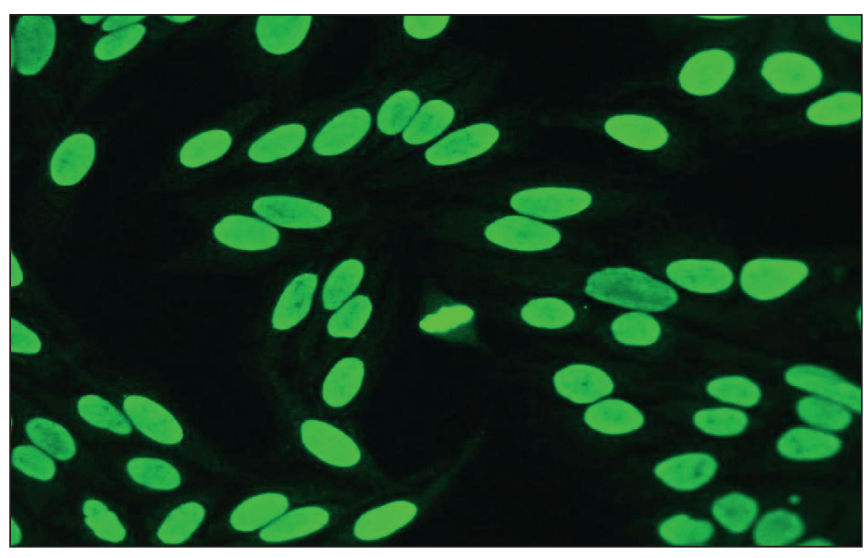

Fig. 1. HEp-2 cells in indirect immunofluorescence. Homogeneous pattern associated with the presence of anti-nucleosome antibodies.

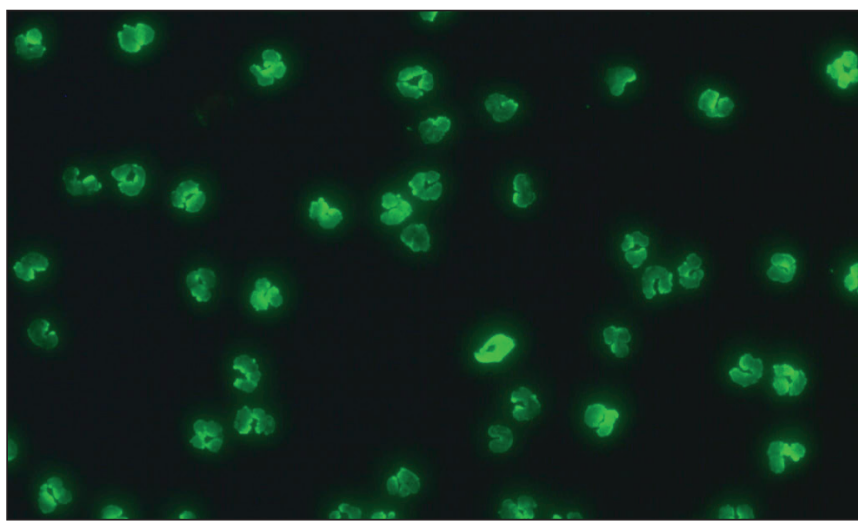

Fig. 3. Perinuclear fluorescence image (pANCA) on human neutrophil in the IIFT image

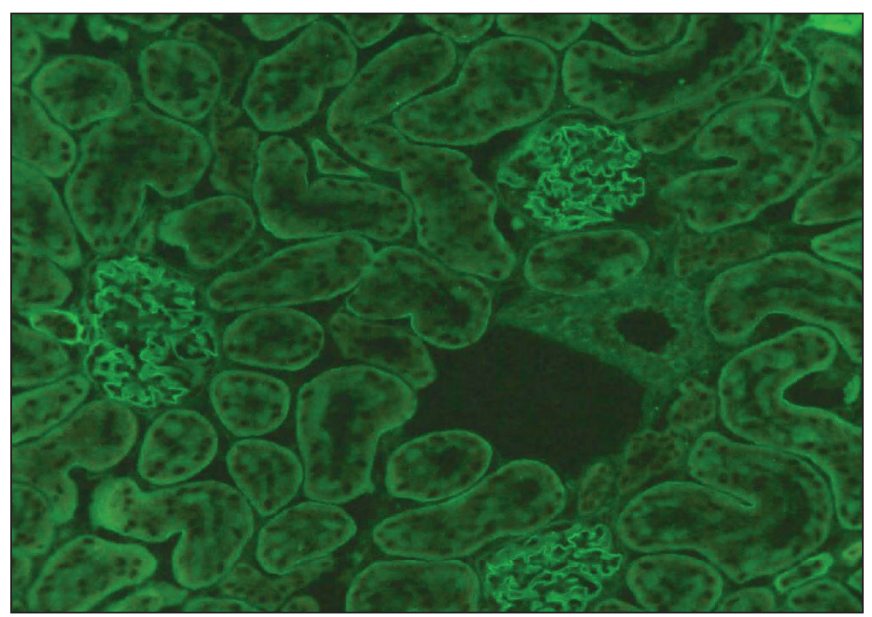

Fig. 5. Anti-GBM antibodies observed in liver kidney image using IIFT method.

According to the latest classification, it is included in the group of diseases associated with inflammation of small vessels. The target antigen for anti-GBM antibodies is the non-collagen NC domain of the 3 alpha chain collagen type IV (alpha3 (IV) NC1) located in the basement membrane of the glomeruli. Clinical manifestations in Goodpasture's disease are associated with glomeruli where inflammation

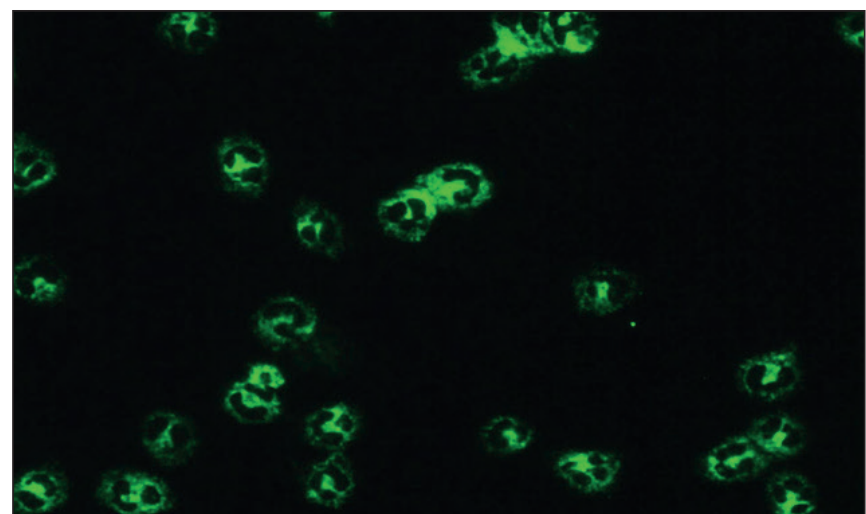

Fig. 2. Cytoplasmic fluorescence image (CANCA) on human neutrophils in the IIFT image.

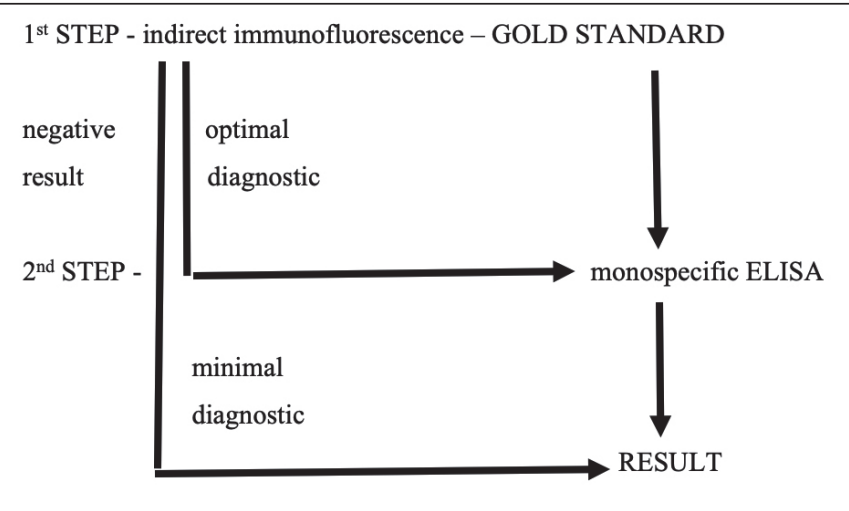

Fig. 4. Recommendations from 1999 recommend a two-steps ANCA antibody evaluation strategy (International Consensus Statement on Testing and Reporting ANCA):

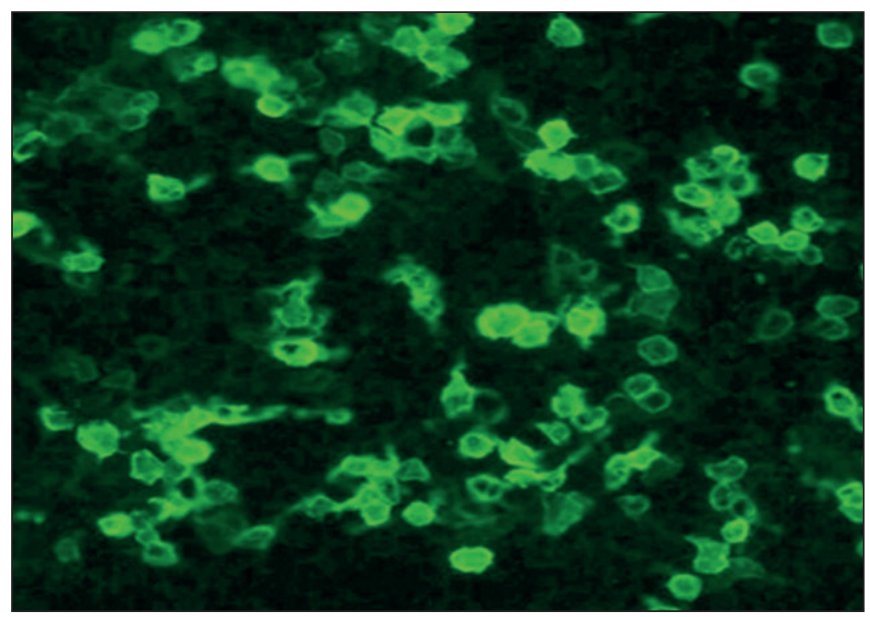

Fig. 6. Image of anti-PLA2R antibodies on HEK 293 transfected cells obtained by IIFT.

usually results in severe, rapidly progressive inflammation. glomeruli and with respiratory symptoms.

When modern treatment induced, renal function is preserved in less than $1 / 3$ of patients during 6 months of follow-up. Cui Z et al. proved that anti-GBM antibodies can also appear in the serum of healthy patients in lower titers. Anti-GBM antibodies have a high prognostic value, and can 
Magdalena Ratajczak et al.

Table 1. The frequency of CANCA antibodies is:

\begin{tabular}{cc}
\hline Generalized Wegener's Granulomatosis (WG) (including glomerulonephritis) & $>90 \%$ \\
\hline WG limited (without glomerulonephritis) & $70 \%$ \\
\hline Microscopic vasculitis (MPA) & $>30 \%$ \\
\hline
\end{tabular}

Table 2. Antibodies to pANCA occur in such diseases as:

\begin{tabular}{cc}
\hline & Prevalence \\
\hline Microscopic vasculitis (MPA) & $42-70 \%$ \\
\hline Churg-Strauss Syndrom(CSS) & $18-60 \%$ \\
\hline Inflammatory bowel's diseases & $67 \%$ \\
\hline Primary sclerosing cholangitis & $?$ \\
\hline Autoimmune liver diseases & $?$ \\
\hline Collagenosis (SLE) & $9-25 \%$ \\
\hline Rheumatoid Arthritis & $3-20 \%$ \\
\hline cancers & $?$ \\
\hline infections & $?$
\end{tabular}

be detected by IIFT (Fig. 5), ELISA and Immunoblot [29].

\section{ANTIBODIES AGAINST M-TYPE PHOSPHOLIPASE A2 RECEPTOR (PLA2R)}

Membranous nephropathy $\mathrm{MN}$ is a major cause of nephrotic syndromes in Caucasian adults. Most often in men over 40 years of age. In children, the disease is rare - often as a result of hepatitis B infection. The cause of the disease in adults remains unknown. Membrane nephropathy belongs to a family of kidney diseases associated with inflammation and hypersensitivity of the glomeruli and / or interstitial tissue. The basis of the disease is morphological changes within the glomerular basement membrane, which is damaged by the interaction of immune complexes [4] Therefore, proteinuria $(>3.5 \mathrm{~g} / 24 \mathrm{~h})$ is observed in patients, often with nephrotic syndrome. Prolonged increased urinary protein leads to an increased risk of chronic renal failure. In addition, patients with $\mathrm{MN}$ are more likely to have thromboembolic and cardiovascular complications, which may result in death [30].

The immunopathogenesis of the primary form of membranous glomerulonephritis was discovered in 2009 when Beck et al. discovered a circulating protein with a mass of $185 \mathrm{kDa}$ by Western Blott method. These were antibodies directed against the phospholipaseA2 (transmembrane glycoprotein) anti-PLA2R receptor. To date, two groups of PLA2 receptor ( $\mathrm{M}$ and $\mathrm{N}$ ) have been described. Type $M$ is the main antigen targeted for anti-PLA2R antibodies. The dominant subclass of Anti-PLA2R antibodies is IgG4. They were detected in $70 \%$ of patients with the primary form of KZN as opposed to the secondary form where they are not detectable [4]. PLA2R receptors are located on the surface of podocytes in human glomeruli and consist of 2 domains: extracellular and intracellular. Anti-PLA2R antibodies activate complement, overproduction of laminin and collagen IV, and thus damage to podocytes and glomeruli (proteinuria). We can detect anti-PLA2R antibodies in patients' serum by two methods:
1. Indirect Immunofluorescence (IIFT) - the substrate is plasmid transfected with formaldehyde-fixed HEK 293 cells. HEK293 cells have a complementary DNA strand for the PLA2R isoform (Fig. 6).

2. The ELISA-antigen is a human recombinant extracellular domain of the receptor purified from solid-transfected cells.

The level of Anti-PLA2R antibodies correlates with disease activity and proteinuria in the primary MN. The decrease in titre may be due to disease remission. The role of PLA2R and anti-PLA2R antibodies in primary membranous glomerulonephritis is unknown [1]. Recent studies say that in addition to the PLA2R protein, there are other antigens that may play a role in the development of primary membranous glomerulonephritis. Such antigens include the basal glomerular membrane antigen - neutral endopeptidase (NEP). The next type of antigens are cytoplasmic cell components: aldose reductase (AR), SOD2, alpha-enolase [31, 32].

Genetic conditions of primary $\mathrm{MN}$ are also suggested. This is due to the DQA1 gene (HLA) polymorphism in the $\mathrm{M}$ receptor of fospolipase $\mathrm{A} 2$. It is believed that the presence of the homozygous form of DQA1 polymorphisms increases immunogenicity in nephropathy. This system activates the lectin path of the complement system and thereby activates the production of antibodies against PLA2R. In the case of heterozygous forms of the DQA1 gene, the immune response is activated by viruses and bacteria. There is also a hypothesis that bacteria and viruses stimulate Toll-like cells, but they activate B lymphocytes to produce Anti-PLA2R antibodies $[33,34]$.

\section{DISCUSSION}

Differentiating the primary and secondary forms of $\mathrm{MN}$ is an important element when choosing the right treatment. Treatment of glomerulonephritis is multidirectional. Its purpose is to stop the progression of kidney damage. In the primary form, immunosuppression is most often used, while in the secondary form, cure or optimal control of the disease that causes membranous $\mathrm{MN}$ is crucial. The clinical and histopathological picture of kidney biopsy plays a huge role in the diagnosis of glomerulonephritis. The clinical picture does not always correlate with the histological picture. Therefore, $\mathrm{MN}$ can be divided into clinical and histological types of MN. The same clinical picture may have different etiologies, and the same cause of the disease may give a different histological picture. Therefore, the basis for the diagnosis of glomerulonephritis is a kidney biopsy and observation of kidney tissue under a light, fluorescent or electron microscope. The characteristic picture of changes allows to diagnose the disease [5]. 
Recent studies show the huge role of antibodies involved in disease development that are useful in the diagnosis and differentiation of membranous nephropathy. The ability to detect the level of antibodies can facilitate both the diagnosis and the distinction of primary and secondary forms without invasive methods for diagnosing MN.

Autoantibody determination is useful in monitoring disease activity and treatment efficacy. The most important parameters of the examined include antinuclear antibodies (ANA), anti-neutrophil cytoplasmic antibodies (ANCA), anti-glomerular basement antibodies (anti-GBM) and phospholipase A2 receptor antibodies (anti-PLA2R). In 2009, Beck and colleagues found PLA2R antibodies that play an important role both in the diagnosis of membranous nephropathy and differentiation because they were detected in $70 \%$ of patients suffering from primary rather than secondary [31]. Gunnarsson and colleagues, on the other hand, have proven that PLA2R antibodies are absent in patients with membranous lupus nephropathy, which is a secondary disease in the presence of SLE [35]. The secondary form of membranous nephropathy is also characterized in many cases by the presence of ANCA antibodies associated with vasculitis [20]. Anti-DNA antibodies and anti-nucleosomes play a significant role here, as they correlate strongly with disease activity. Cui Z et al. Claim that anti-GBM antibodies have a high prognostic value and may also appear in the serum of healthy patients in lower titers [27].

\section{CONCLUSION}

The above work focuses on serological diagnostics, which is helpful in diagnosing, differentiating as well as monitoring the treatment and estimation of relapses after kidney transplantation in diseases related to glomerulonephritis. In the case of suspected Lupus nephritis, testing for the presence of antinuclear antibodies (ANA), in particular anti-dsDNA, and anti-nucleosomomes is helpful. As for diseases associated with vasculitis in glomerulonephritis, we detect ANCA antibodies. Goodpasture's syndrome is characterized by the presence of Anti - GBM. Novelty are anti-PLA2R antibodies whose incidence in primary membranous glomerulonephritis is $100 \%$.

\section{REFERENCES}

1. Schlumberger W, Hornig N, Lange $S$, et al. Differential diagnosis of membranous nephropathy with autoantibodies to phospholipase A2 receptor 1. Autoimmunity Reviews 13. 2014;108-113.

2. Kalluri R, Cantley LG, Kerjasckhi D, et al. Reactive oxygen species expose cryptic epitopes associated with autoimmune Goodpasture syndrome. J Biol Chem. 2000;275:20027-20032.

3. Wolf $D$, Hochegger $K$, Wolf $A M$, et al. CD4+CD25+ regulatory $T$ cells inhibit experimental anti-glomerular basement membrane glomerulonephritis in mice. J Am Soc Nephrol. 2005;16:1360-1370.

4. Feehally J, Floege J, Johnson RJ. Comprehensive Clinical Nephrology. Elservier, Warszawa, 2003, pp 181-191.

5. Hoxha E, Harendza S, Zahner G, et al. An immunofluorescence test for phospholipase-A2-receptor antibodies and its clinical usefulness in patients with membranous glomerulonephritis. Nephrol Dial Transplant. 2011;26(8):2526-32. doi:10.1093/ndt/gfr247.
6. Scheidat $S$, Stahl RA. Membranous glomerulonephritis. Internist. 2003;44:1120-30.

7. Coons AH, Kaplan MH. Localization of antigen in tissue cells; improvements in a method for the detection of antigen by means offluorescent antibody. J Exp Med. 1950;91:1-13.

8. Goulvestre C. Antinuclear antibodies. Presse Med. 2006; 35:287-295.

9. Granito A, Muratori $P$, Muratori $L$, et al. Antinuclear antibodies giving the 'multiple nuclear dots' or the 'rim-like/membranous' patterns: diagnostic accuracy for primary bil-iary cirrhosis. Aliment Pharmacol Ther. 2006;24:1575-1583.

10. Genth E, Mierau R. Diagnostic significance of scleroderma and myositisassociated autoantibodies. Z Rheumatol. 1995;54:39-49.

11. Suer W, Dahnrich C, Schlumberger W, et al. (EUROIMMUN AG) Autoantibodies in SLE but not in sclero-derma react with proteinstripped nucleosomes. J Autoimmun. 2004;22:325-334.

12. Chung L, Flyckt RL, Colon I, et al. Outcome of pregnancies complicated by systemic sclerosis and mixed connective tissue disease. Lupus. 2006;15:595-599.

13. Pakunpanya $K$, Verasertniyom 0 , Vanichapuntu $M$, et al. Incidence and clinical correlation of anticentromere antibody in Thai patients. Clin Rheumatol. 2006;25:325-328.

14. Respaldiza N, Wichmann I, Ocana C, et al. Anti-centromere antibodies in patients with systemic lupus erythematosus. Scand J Rheumatol. 2006;35: 290-294.

15. Rutjes $S A$, Vree Egberts WT, Jongen $P$, et al. Anti-R052 antibodies frequently co-occur with anti-Jo-1 antibodies in sera from patients with idiopathic inflammatory myopathy. Clinical and experimental immunology. 1997;109:32-40.

16. Balow JE, Boumpas DT, Ausin HA. Systemic lupus erhytematosus and the kidney. In: Lahita RG (ed) Systemic Lupus erythematosus. Academic Press: San Diego, London, Boston, New York, Sydney, Tokyo, Toronto. 1999, pp. 657-685.

17. Stinton LM, Barr SG, Tibbles LA, et al. Autoantibodies in lupus nephritis patients requiring renal transplantation. Lupus. 2007;15:394-400.

18. Isenberg DA, Ravirajan CT, Rahman A, et al. The role of antibodies to DNA in systemic lupus erythematosus-a review and introduction to an international workshop on DNA antibodies held in London. Lupus. 1997;6:290-304.

19. Lloyd W, Schur PH. Immune complexes, complement, and anti-DNA in exacerbations of systemic lupus erythematosus (SLE). Medicine (Baltimore). 1981;60:208-17.

20. Savige J, Pollock W, Trevisin M. What do antineutrophil cytoplasmic antibodies (ANCA) tell us? Best Pract Res Clin Rheumatol. 2005; 19:263-276.

21. Segelmark M, Baslund B, Wieslander J. Some patients with antimyeloperoxidase antibodies have a CANCA pattern. Clin Exp Immunol. 1994;96:458-465.

22. Specks U, Wheatley CL, McDonald TJ, et al. Anticytoplasmic autoantibodies in the diagnosis and follow up of Wegener's granulomatosis. Mayo Clin Proc. 1989;64:28-36.

23. Radice A, Sinico RA. Antineutrophil cytoplasmic antibodies (ANCA). Autoimmunity. 2005;38:93-103.

24. Csernok E, Reichel P, Gross WL. Neue Aspekte der Antineutrophil ezytoplasmatische Antikörper (ANCA)-Diagnostik bei Vaskulitiden. Z Rheumatol. 2002;61:367-377.

25. Cohen Tervaert JW, von Goldschmeding R, dem Borne AEGK, et al. Antimyeloperoxidase antibodies in the Churg Strauss syndrome. Thorax. 1991;46:70-71. 
26. Stöcker W, Olbrich S, Schlumberger W, et al. (EUROIMMUN AG). Autoantibodies to Granulocyty in chronic inflammatory bowel disease are not correlated with antibodies to intestinal goblet cells in ulcerative colitis and to pancreatic juice in Crohn's disease. Immunobiol. 1992;186;96.

27. Burkholder L, Bainton DF. Auto-antigens in Wegener's granulomatosis. Blood. 1990;75:1588-1589.

28. Savige J, Gillis D, Benson E, et al. International Consensus Statement on Testing and Reporting of Antineutrophil Cytoplasmic Antibodies (ANCA). Am J Clin Pathol 1999:111:507-513.

29. HellmarkT, Segelmark M. Diagnosis and classification of Goodpasture's disease (anti-GBM). J Autoimmun. 2014;48-49:108-12.doi:10-1016/j. jaut.2014.01.024.

30. Fervenza FC, Sethi S, Specks U. Idiopathic Membranous Nephropathy: Diagnosis and Treatment. Clin J Am Soc Nephrol. 2008;3:905-919, doi: 10.2215/CJN.04321007.

31. Stahl R, Hoxha E, Fechner K. PLA2R Autoantibodies and Recurrent Membranous Nephropathy after Transplantation. N. Engl. J. Med. 2010;363:496-498.

32. Prunotto M, Carnevali ML, Candiano G, et al. Autoimmunity in membranous nephropathy targets aldose reductase and SOD2. J Am SocNephrol. 2010;21:507-519.

33. Bruschi M, Carnevali ML, Murtas C, et al. Direct characterization of target podocyte antigens and auto-antibodies in human membranous glomerulonephritis: Alfa-enolase and borderline antigens. J Proteomics. 2011;74:2008-2017.

34. Stanescu HC, Arcos-Burgos M, Medlar A, et al. Risk HLA-DQA1 and PLA(2)R1 alleles in idiopathic membranous nephropathy. N Engl J Med. 2011;364:616-626.

35. Gunnarsson I, Schlumberger W, Ronnelid J. Antibodies to M-type phospholipase $A 2$ receptor (PLA2R) and membranous lupus nephritis. Am J Kidney Dis. 2012;59:585-6.

\section{ORCID and contributionship}

Magdalena Ratajczak - 0000-0002-2864-4305 A,B,D,F

Ewa Poleszak - 0000-0003-4359-3953 B,D

Tomasz Chrościcki - 0000-0002-8130-1467 E,F

\section{Conflict of interest}

Authors declare no conflict of interest.

\section{CORRESPONDING AUTHOR Magdalena Ratajczak \\ Euroimmun Poland a PerkinElmer Company, \\ Widna 2a, 50-543 Wroclaw \\ e-mail:m.ratajczak@euroimmun.pl}

Received: 06.07.2020

Accepted: 07.09.2020

A - Work concept and design, B - Data collection and analysis, C - Responsibility for statistical analysis,

D-Writing the article, $\mathbf{E}$-Critical review, $\mathbf{F}$ - Final approval of the article 